\title{
Coupled DTA-TGA-FT-IR investigation of pyrolytic decomposition of EVA, PVC and cellulose
}

\author{
Yannick Soudais ${ }^{\mathrm{a}, *}$, Ludivine Moga ${ }^{\mathrm{a}}$, Jaroslav Blazek ${ }^{\mathrm{a}}$, \\ Florent Lemort ${ }^{\mathrm{b}}$ \\ ${ }^{a}$ UMR CNRS 2392, Laboratoire de Génie des Procédés des Solides Divisés, École des Mines d'Albi-Carmaux, \\ Campus Jarlard, 81013 Albi, France \\ ${ }^{\mathrm{b}}$ CEA Valrhô-Marcoule, Laboratoire de Procédés Innovants de Conditionnement (LPIC), BP 17171, \\ 30207 Bagnols-sur-Cèze Cedex, France
}

\begin{abstract}
The behavior of individual polymers (EVA, PS, PVC and cellulose) was investigated under pyrolysis at different heating rates. A kinetic model is proposed for the weight loss and compared with the experimental results and the kinetic parameters were determined and compared with the available published data. IR spectrometric analysis was used to follow the evolution of the gaseous pyrolysis products versus the temperature. Analysis of online FT-IR spectra confirmed the initial loss of acetic acid for EVA and one $\mathrm{HCl}$ for PVC.
\end{abstract}

Keywords: DTA; TGA; Polymer

\section{Introduction}

The thermal degradation of widely used polymers or biopolymers (EVA, PE, PP, PS, PVC, PET, cellulose, lignin, etc.) has been described in the literature. The pyrolysis of these polymers has been studied in detail and many published articles describe the mechanism and rate of decomposition. Waste pyrolysis could be a clean alternative to incineration because this process combines material recovery with energy production and minimizes the ultimate residues. In Europe there is currently rising interest in biomethanization, pyrolysis and vitrification processes as alternatives to incineration. The objective of our research is to investigate the degradation under pyrolysis conditions of binary mixtures of polymers in which one of the components is EVA. In order to better understand the process in these mixtures, we first investigated the behavior of individual polymers: EVA, PS, PVC and cellulose. This investigation is the subject of this paper. The innovative aspect of these results is the use of a thermobalance connected to an FT-IR spectrometer via a

\footnotetext{
* Corresponding author.

E-mail address: Yannick.soudais@enstimac.fr (Y. Soudais).
}

heated line allowing continuous recording of the IR spectra with identification of the evolved gas.

EVA (ethylene vinyl acetate) with different percentages of vinyl acetate (VA) is very extensively used, especially in the production of cables, piping, adhesive tape, etc. Ethylene vinyl acetate copolymers represent the largest volume segment of the ethylene copolymer market. Their properties depend on the VA content: products ranging from 2 to $40 \%$ VA are marketed for different purposes. An extensive bibliography [1-19] is available on the degradation of EVA and the estimated kinetic parameters of the process. Basically, the thermal degradation of EVA copolymers is a two-step process. The first step, occurring in the temperature range from 300 to $400{ }^{\circ} \mathrm{C}$, consists in the elimination of one acetic acid molecule, leading to the formation of an ethylene structure on the rest of the carbon chain instead of the previous carbonyl function group. For this reaction, the radical mechanism and ionic elimination have been proposed [15]. PEA (poly[ethylene-co-(acetylene)]), formed in the first stage, begins to decompose into smaller chains by the mechanism of the random splitting of the carbon skeleton. This second stage occurs around $425^{\circ} \mathrm{C}$ [16] or $470{ }^{\circ} \mathrm{C}$ [17]. The decomposition of the acetoxy groups is favored by the tendency to form a six-ring transition state (via a hydrogen bond with active methylene 
groups). The activated complex decomposes thermally, eliminating the acetic acid [18].

The thermal degradation of PS is a radical chain mechanism, where initiation, propagation and termination reactions are the relevant reaction classes. Two types of initiation reactions can be identified [3]. It has been shown that styrene is the primary PS decomposition product [20]. Various kinetic models have been proposed in the literature. Marcilla and Beltran [19] analyzed two types of models, and concluded that the best models are those that involve the formation of an intermediate species, with gases generated in two stages. They also chose this model for the degradation of EVA.

The thermal degradation of PVC has been the subject of numerous investigations and various kinetic models have been proposed in the literature [21-27,32,33] to quantitatively describe the chemical reactions that take place during PVC pyrolysis. It is generally considered a two- or three-step process (depending on the authors) in which the first step is the loss of one $\mathrm{HCl}$ molecule by a free radical mechanism beginning at about $200{ }^{\circ} \mathrm{C}$ and resulting in the formation of polyene in competition with the formation of a cross-linked structure involving different chain radicals. The second and third steps are parallel reactions, occurring in the range $350-520{ }^{\circ} \mathrm{C}$. Cracking of some carbon-carbon bonds of the previous polyene structures occurs where monocyclic and polycyclic aromatics compounds like benzene, toluene and naphthalene derivatives obtained by cyclization of the conjugated olefin intermediate structures are formed rather than aliphatic structures.

Cellulose is the most widely studied substance in the field of wood and biomass. The kinetics of cellulose pyrolysis have been extensively investigated by numerous researchers and many kinetic schemes have been proposed [28-32,26]. Despite the research effort, however, the various mechanisms are not fully known. The degradation of cellulose consists of a complex set of reactions. Font et al. showed that the modified KilzerBroido (KBM) model of kinetic thermal decomposition of cellulose yields the best results, and that with all models that take the activation of cellulose into account (with the formation of anhydrocellulose in the first step) the agreement between experimental and calculated values increases.

\section{Experimental}

\subsection{Materials}

All samples in the present study (EVA, PS, PVC and cellulose) were pure polymers from Aldrich Chemical Company. EVA samples with 12, 25 and 40\% VA content weighing between 20 and $40 \mathrm{mg}$ were used to investigate the pyrolysis of EVA.

\subsection{Thermogravimetric and online FT-IR analysis}

The samples were placed in the platinum crucible of the thermobalance. Heating rates ranging from 1 to $30{ }^{\circ} \mathrm{C} \mathrm{min}{ }^{-1}$ were applied $\left(1,2,5,7,10,15,20\right.$ and $30{ }^{\circ} \mathrm{C} \min ^{-1}$ for PS; 5, 7, 10, 15, 20 and $30{ }^{\circ} \mathrm{C}$ min $^{-1}$ for EVA; 5, 10, 20 and $30{ }^{\circ} \mathrm{C} \mathrm{min}{ }^{-1}$ for PVC; 10 and $30{ }^{\circ} \mathrm{C} \mathrm{min}{ }^{-1}$ for cellulose) and duplicate runs were carried out at all heating rates. Pyrolysis was carried out in $\mathrm{N}_{2}$ atmosphere, with the gas flow maintained at $27 \mathrm{~cm}^{3} \mathrm{~min}^{-1}$. The data measured are the mass loss and temperature, the curve were obtained in \% of mass loss versus temperature and the apparatus calculate the curve DTG which means d(\% mass loss)/ $\mathrm{d} t$. A Setaram model TGA 92-16 thermobalance was connected to the FT-IR spectrophotometer by means of a heated line to allow continuous recordings of the IR spectra corresponding to the evolved gases. The spectrophotometer was a Perkin-Elmer System 2000 equipped with a gas cell and a DTGS detector. The heated line and gas-cell were temperature-regulated and maintained at $250{ }^{\circ} \mathrm{C}$ to prevent unwanted condensation and guarantee the most quantitative transfer possible of gaseous decomposition products and high detection sensitivity. The evolved gases were continuously recorded with TimeBase ${ }^{\circledR}$. The Gram-Schmidt Fourier transform provides the corresponding spectra for each time interval. FT-IR spectra were recorded for wave numbers ranging from 4000 to $400 \mathrm{~cm}^{-1}$ with a spectral resolution of $8 \mathrm{~cm}^{-1}$. Throughout experiment the spectrophotometer recorded the spectra corresponding to the evolved gases in a 2-4s interval (depending on the heating rate). Spectrum analysis was performed with the KnowItAll ${ }^{\circledR}$ analytical system.

\section{Results and discussion}

For all the TGA analysis curves the initial and final decomposition temperatures were variable, and the temperature increased with the heating rate, as expected.

\subsection{Analysis of results for EVA and PS}

\subsubsection{Interpretation of experimental curves}

The following experimental data were recorded: weight loss percentages, temperatures of DTG peaks observed and DTG value.

3.1.1.1. EVA. The TGA curves for EVA copolymers with different weight percentages of VA are all of similar shape. Two weight losses were observed. Although the initial temperature was $250{ }^{\circ} \mathrm{C}$, the weight loss was relatively minor up to $300{ }^{\circ} \mathrm{C}$. The decomposition rate suddenly increased between 300 and $350{ }^{\circ} \mathrm{C}$. The higher the percentage of vinyl acetate, the greater the first weight loss. At about $350{ }^{\circ} \mathrm{C}$, the curve shows an inflection point with a shoulder extending to $400{ }^{\circ} \mathrm{C}$, corresponding to a slight weight loss (a plateau on the TGA curve). Above $400{ }^{\circ} \mathrm{C}$ the weight loss sharply increases again. It

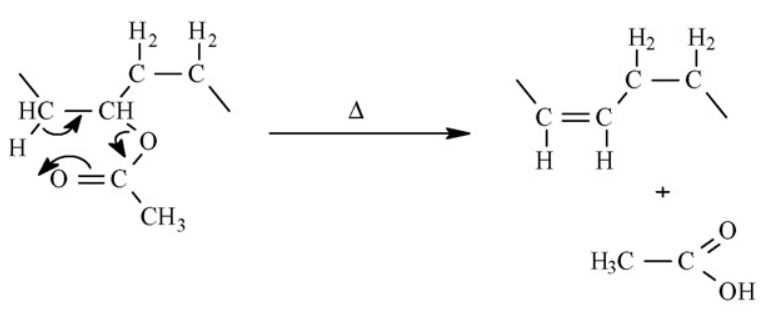

Fig. 1. Thermal degradation mechanism of EVA (step 1): release of an acetic acid molecule. 
Table 1

Weight losses, DTG values, and DTG peak temperatures for EVA

\begin{tabular}{|c|c|c|c|c|c|c|}
\hline \multirow[t]{2}{*}{$\begin{array}{l}\text { Heating rate } \\
\left({ }^{\circ} \mathrm{C} \min ^{-1}\right)\end{array}$} & \multicolumn{2}{|c|}{$\begin{array}{l}\text { DTG peak } \\
\text { temperature }\left({ }^{\circ} \mathrm{C}\right)\end{array}$} & \multicolumn{2}{|c|}{$\begin{array}{l}\text { DTG value } \\
(\% / \mathrm{min})\end{array}$} & \multicolumn{2}{|l|}{$\begin{array}{l}\text { Weight } \\
\text { loss }(\%)\end{array}$} \\
\hline & First loss & Second loss & First loss & Second loss & First loss & Second loss \\
\hline 5 & 345 & 461 & -1.9 & -10.5 & 22.4 & 77.6 \\
\hline 10 & 355 & 474 & -3.6 & -20.5 & 28.5 & 71.5 \\
\hline 20 & 367 & 483 & -6.8 & -29.8 & 27.2 & 72.8 \\
\hline 30 & 375 & 489 & -8.75 & -37.25 & 28.4 & 71.6 \\
\hline
\end{tabular}

is commonly acknowledged that in the initial temperature range (i.e. up to $350{ }^{\circ} \mathrm{C}$ ) thermal decomposition is attributable to the release of acetoxy groups from the grafted chains, resulting in the elimination of an acetic acid molecule (Fig. 1). The second weight loss is due to the rupture of the hydrocarbon chains formed during the first step. Since the weight loss is proportional to the percentage of VA, a quantitative determination method can be developed. The DTG curves demonstrate that the decomposition rate of the acetoxy groups reaches a maximum at $300{ }^{\circ} \mathrm{C}$. Almost all the acetoxy groups have been released at $350{ }^{\circ} \mathrm{C}$.

Table 1 indicates the weight loss, the DTG peak temperatures (maximum degradation rate) and the DTG value observed during pyrolysis of EVA for various heating rates.

3.1.1.2. PS. The thermogram for PS degradation reveals a single weight loss.

Table 2 indicates the weight loss, the DTG peak temperatures (maximum degradation rate) and the DTG value observed during pyrolysis of PS for various heating rates.

\subsubsection{Kinetic model and data analysis}

After reviewing the available published models, we decided to test the second model proposed by Marcilla and Beltran [17], which is the same for PS and EVA:
Table 2

Weight losses, DTG values, and DTG peak temperatures for PS (5, 10 and $20{ }^{\circ} \mathrm{C} \min ^{-1}$ )

\begin{tabular}{lll}
\hline $\begin{array}{l}\text { Heating rate } \\
\left({ }^{\circ} \mathrm{Cmin}^{-1}\right)\end{array}$ & $\begin{array}{l}\text { DTG peak } \\
\text { temperature }\left({ }^{\circ} \mathrm{C}\right)\end{array}$ & $\begin{array}{l}\text { DTG value } \\
(\% / \mathrm{min})\end{array}$ \\
\hline 5 & 413 & -14.7 \\
10 & 426 & -24.6 \\
20 & 440 & -42.9 \\
\hline
\end{tabular}

$=K t+T_{0}(\mathrm{~K}) ; T_{0}$ the initial sample temperature $(\mathrm{K}) ; K$ the heating rate $\left(\mathrm{K} \mathrm{min}^{-1}\right) ; w$ the weight (EVA or PS) $(\mathrm{g}) ; w^{*}$ the weight of intermediate species $\left(\mathrm{EVA}^{*}\right.$ or PS $\left.{ }^{*}\right)(\mathrm{g})$.

A fourth-order Runge-Kutta numerical solution method was applied here, using the built-in ODE45 function in MATLAB. The kinetic parameters were optimized by loopback tests so that four or six kinetic parameters were optimized (two frequency factors and two activation energies for PS, three frequency factors and three activation energies for EVA) each time the model was recalculated. The reaction order was systematically assigned a value of $n=1$.

The experimental and calculated weight losses (the model implies the formation of an intermediate reaction product PS* or EVA* during the simulation) were in perfect agreement, as shown in Fig. 2.

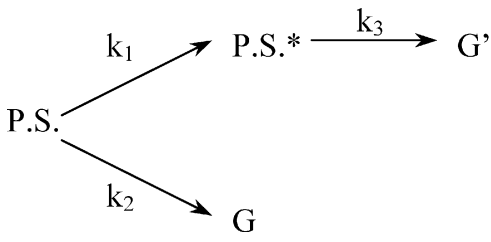

$\left[\frac{\mathrm{d} w}{\mathrm{~d} t}=-A_{1} \exp \left(-\frac{E_{\mathrm{a} 1}}{R T}\right) w^{n}-A_{2} \exp \left(-\frac{E_{\mathrm{a} 2}}{R T}\right) w^{m}\right]_{K}$
$\left[\frac{\mathrm{d} w^{*}}{\mathrm{~d} t}=A_{1} \exp \left(-\frac{E_{\mathrm{a} 1}}{R T}\right) w^{n}-A_{3} \exp \left(-\frac{E_{\mathrm{a} 3}}{R T}\right) w^{* p}\right]_{K}$

where the total sample weight at any given time is: $W(T)=w+w^{*} ; t$ the time (min); $n, m$ and $p$ the reaction order; $A_{1}, A_{2}$ and $A_{3}$ the pre-exponential factor $\left(\mathrm{min}^{-1}\right) ; E_{\mathrm{a} 1}, E_{\mathrm{a} 2}$ and $E_{\mathrm{a} 3}$ the activation energy $\left(\mathrm{J} \mathrm{mol}^{-1}\right) ; R$ the ideal gas constant $=8.3136\left(\mathrm{~J} \mathrm{~mol}^{-1} \mathrm{~K}^{-1}\right) ; T$ the sample temperature
The values indicated in the second column of Tables 3 and 4 correspond to the overall mean of 15 parameters calculated for three EVA at five different heating rates.

All the values obtained after optimization for PS and EVA were consistent and very near those reported by Marcilla and Beltran [17], with the exception of the $A_{1}$ parameter for EVA. In this case, the calculated values (not indicated here) were very different from the values proposed by Marcilla and Beltran [17] and varied significantly with the VA weight fraction in the EVA test sample.

In the case of PS the pre exponential factors $A_{2}=0 \mathrm{~min}^{-1}$ and the value of $E_{\mathrm{a} 2}$ is infinity indicate the step is not 

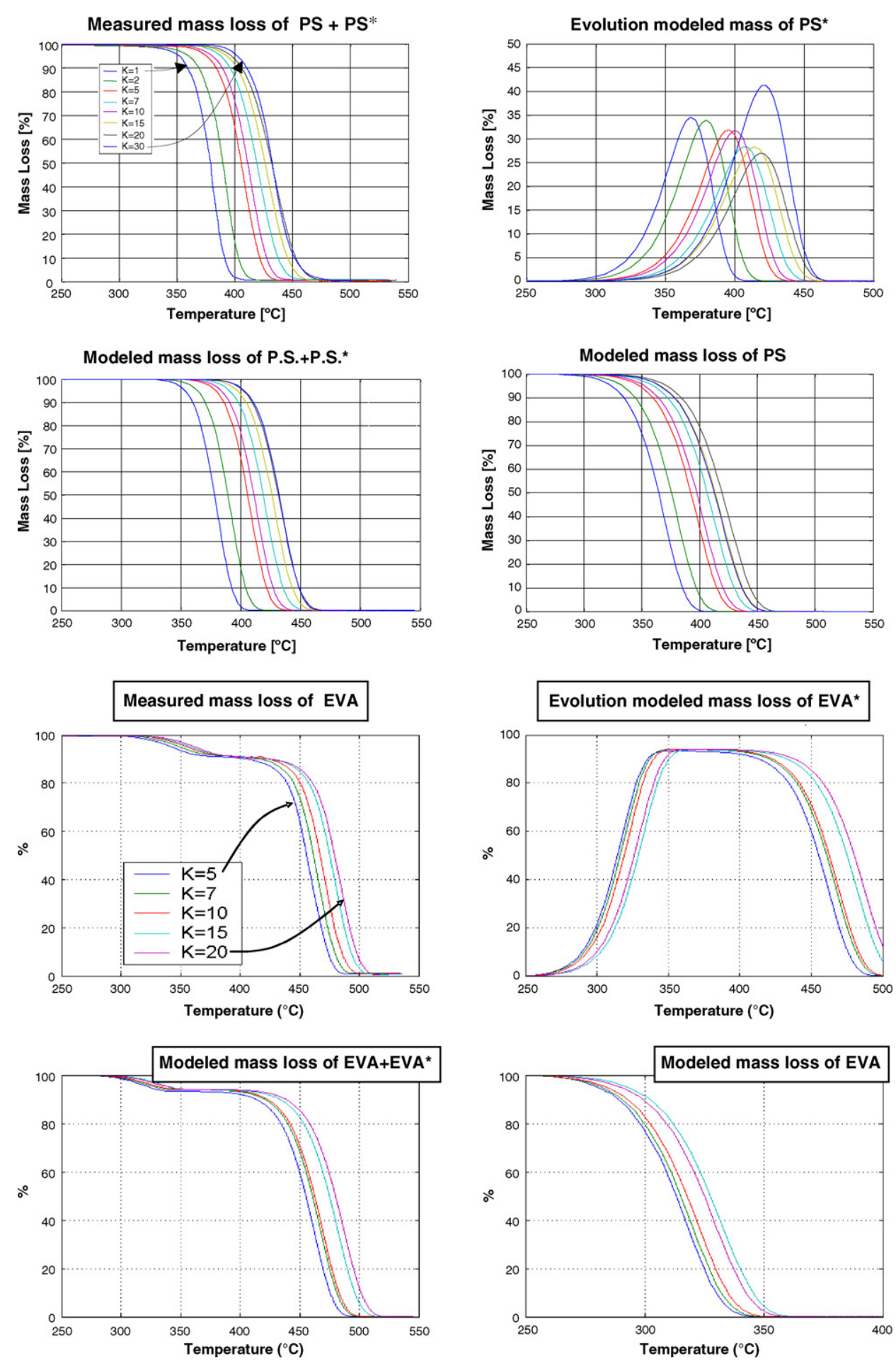

Fig. 2. Experimental and modeled weight loss vs. temperature for PS and EVA.

present and gases $\mathrm{G}$ are not obtained: the model could be simplified.

EVA is a block copolymer with the following molecular formula:

$$
\left(-\mathrm{CH}_{2}-\mathrm{CH}_{2}-\right)_{x}\left(-\mathrm{CH}_{2} \mathrm{CH}\left(\mathrm{O}_{2} \mathrm{CCH}_{3}\right)-\right)_{y}
$$

A correlation equation $A_{1}=B(\mathrm{VA} \%)^{M}$ was established and selected in GtkGraph with the following values, with the smallest possible residue using a least-squares method:

- $B=446.803 \times 10^{16} \mathrm{~min}^{-1}$

- $M=-1.38914$;

- residue $=0.0138466$.

The equation and coefficients were supplied to a new MATLAB program that plots the weight loss versus time for all 
Table 3

Kinetic parameters obtained for PS decomposition

\begin{tabular}{lll}
\hline & $\begin{array}{l}\text { Marcilla and } \\
\text { Beltran [17] }\end{array}$ & $\begin{array}{l}\text { Simulation } \\
\text { values }\end{array}$ \\
\hline$A_{1}$ & $2.01 \times 10^{14} \mathrm{~min}^{-1}$ & $2.21 \times 10^{14} \mathrm{~min}^{-1}$ \\
$A_{2}$ & $0 \mathrm{~min}^{-1}$ & $0 \mathrm{~min}^{-1}$ \\
$A_{3}$ & $2.60 \times 10^{16} \mathrm{~min}^{-1}$ & $2.64 \times 10^{16} \mathrm{~min}^{-1}$ \\
$E_{\mathrm{a} 1}$ & $191.950 \mathrm{~kJ} \mathrm{~mol}^{-1}$ & $191.989 \mathrm{~kJ} \mathrm{~mol}^{-1}$ \\
$E_{\mathrm{a} 2}$ & $2085.4 \mathrm{~kJ} \mathrm{~mol}^{-1}$ & - \\
$E_{\mathrm{a} 3}$ & $216.500 \mathrm{~kJ} \mathrm{~mol}^{-1}$ & $216.482 \mathrm{~kJ} \mathrm{~mol}^{-1}$ \\
\hline
\end{tabular}

types of EVA and all heating rates, with the VA percentage as the parameter. The result was extrapolated to all types of EVA from 10 to $100 \%$ VA (Fig. 3).

The expected plateau heights were obtained and the shape of the curves was fully consistent with experimental results (Table 5). The time scale is in seconds. To assess the accuracy of the curves, we then calculated VA\% from the equation: $\mathrm{VA} \%=1.434\left(1-x\left(T_{\text {plateau }}\right)\right)$.

\subsection{Analysis results for PVC and cellulose}

\subsubsection{Interpretation of experimental curves}

3.2.1.1. Experimental results for PVC. Table 6 shows the temperatures of the DTG peaks (maximum degradation rate) observed during pyrolysis of PVC. The shape of the thermogram indicates three weight losses.

Note that the thermogram indicates only two peaks for a heating rate of $30{ }^{\circ} \mathrm{C} \mathrm{min}{ }^{-1}$; at a fast heating rate the degradations are recorded simultaneously and the peaks are superimposed.

3.2.1.2. Experimental results for cellulose. Only heating rates of 10 and $30{ }^{\circ} \mathrm{C} \mathrm{min}{ }^{-1}$ were tested for cellulose. The thermogram indicates a single weight loss (Table 7).

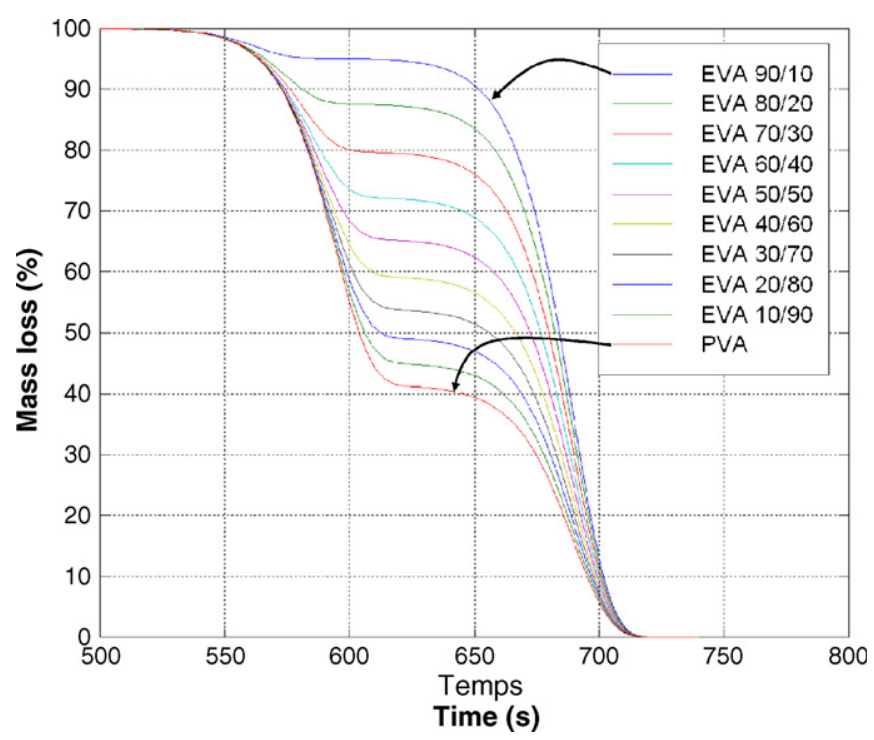

Fig. 3. Relative weight loss $\left(E V A+E^{*}{ }^{*}\right)$ vs. time according to VA percentage.
Table 4

Kinetic parameters obtained for EVA decomposition

\begin{tabular}{lll}
\hline & $\begin{array}{l}\text { Marcilla and } \\
\text { Beltran [17] }\end{array}$ & $\begin{array}{l}\text { Simulation } \\
\text { values }\end{array}$ \\
\hline$A_{1}$ & $1.48 \times 10^{15} \mathrm{~min}^{-1}$ & $f(\% \mathrm{VA})$ \\
$A_{2}$ & $8.79 \times 10^{16} \mathrm{~min}^{-1}$ & $8.06 \times 10^{16} \mathrm{~min}^{-1}$ \\
$A_{3}$ & $8.23 \times 10^{18} \mathrm{~min}^{-1}$ & $8.46 \times 10^{18} \mathrm{~min}^{-1}$ \\
$E_{\mathrm{a} 1}$ & $197.2 \mathrm{~kJ} \mathrm{~mol}^{-1}$ & $198.0 \mathrm{~kJ} \mathrm{~mol}^{-1}$ \\
$E_{\mathrm{a} 2}$ & $207.4 \mathrm{~kJ} \mathrm{~mol}^{-1}$ & $207.9 \mathrm{~kJ} \mathrm{~mol}^{-1}$ \\
$E_{\mathrm{a} 3}$ & $272.3 \mathrm{~kJ} \mathrm{~mol}^{-1}$ & $272.4 \mathrm{~kJ} \mathrm{~mol}^{-1}$ \\
\hline
\end{tabular}

Reaction order: $n=m=p=1$.

\subsubsection{Kinetic model and data analysis}

3.2.2.1. PVC model. We tested one of the models proposed by Marcilla and Beltran [20]:

$\mathrm{PVC} \stackrel{K_{1}^{\prime}}{\longrightarrow} a \mathrm{HCl}+b \mathrm{PVC}^{*}$

$b \mathrm{PVC}^{*} \stackrel{K_{2}^{\prime}}{\longrightarrow} c \mathrm{G}+e \mathrm{RS}$

$e \mathrm{RS} \stackrel{K_{3}^{\prime}}{\longrightarrow} f \mathrm{G}^{\prime}+g \mathrm{RS}^{*}$

The kinetic equations are the following:

$$
\begin{aligned}
\mathrm{dPVC} & =-k_{1}^{\prime} \exp \left(-\frac{E_{\mathrm{a} 1}^{\prime}}{R T}\right)[\mathrm{PVC}] \\
\mathrm{dPVC}^{*} & =b\left(k_{1}^{\prime} \exp \left(-\frac{E_{\mathrm{a} 1}^{\prime}}{R T}\right)[\mathrm{PVC}]\right. \\
& \left.-k_{2}^{\prime} \exp \left(-\frac{E_{\mathrm{a} 2}^{\prime}}{R T}\right)\left[\mathrm{PVC}^{*}\right]\right) \\
\mathrm{dRS}= & e\left(k_{2}^{\prime} \exp \left(-\frac{E_{\mathrm{a} 2}^{\prime}}{R T}\right)\left[\mathrm{PVC}^{*}\right]-k_{3}^{\prime} \exp \left(-\frac{E_{\mathrm{a} 3}^{\prime}}{R T}\right)[\mathrm{RS}]\right)
\end{aligned}
$$

$\mathrm{dRS}^{*}=g\left(k_{3}^{\prime} \exp \left(-\frac{E_{\mathrm{a} 3}^{\prime}}{R T}\right)[\mathrm{RS}]\right)$

$\mathrm{dPVC}_{\text {total }}=\mathrm{dPVC}+\mathrm{dPVC}^{*}+\mathrm{dRS}$

Fig. 4 confirms the very close agreement between the experimental results and the values simulated using the model selected for pyrolysis of PVC alone. The intermediate species and their stability zones account for the experimental curve obtained.

3.2.2.2. Cellulose model. Cellulose is assumed to decompose according to two parallel reactions as shown in the following Broido-Shafizadeh reaction scheme:

Complex kinetic models are found in the literature based on the multistage reaction mechanism described in the preceding figure. Generally, however, thermal degradation is restricted to a single step and its kinetics are described by the following simple equation $[26,31]$ :

dcellulose $=k_{0} \exp \left(-\frac{E}{R T}\right)(1-[$ cellulose $]) \times[\text { cellulose }]^{0.5}$ 


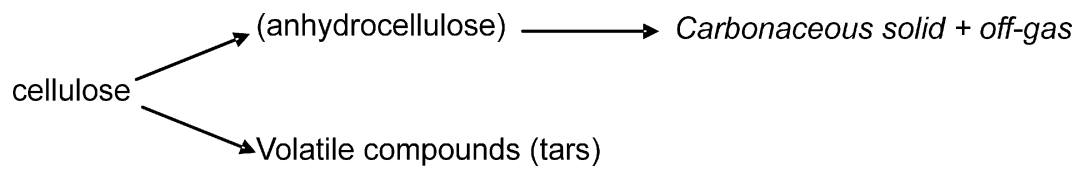

The experimental approach presented in this article involves dynamic thermogravimetric analysis, with discrimination of the published kinetic equations for thermal decomposition of solids.

The reaction rate is expressed as follows:

$\frac{\mathrm{d} X}{\mathrm{~d} t}=k_{0} \exp \left(-\frac{E}{R T}\right) f(X)$

in which $X$ represents solid conversion rate and $f(X)$ is a mathematical function depending on the presumed reaction mechanism (Table 8).

Prior studies have shown that the most suitable basis for modeling the kinetics of cellulose degradation are the reaction order model and the Prout-Tomkins equation, which was therefore adopted for this study.

The results obtained with the model (Fig. 5) differed from the experimental values, although the model closely approximated reality except for the final stage. This deviation justifies the published corrective terms applied to the Prout-Tomkins equation.

\subsection{Conclusion: experimental results and MATLAB simulations}

Modeling the kinetic equations in MATLAB allowed us to compare the published theoretical models with our experimental results. The good agreement between the selected models and the experimental values encouraged us to consider the models valid to correlate the mass loss with the gases identified by FT-IR in the following sections.

\subsection{Analysis of FT-IR results for evolved pyrolysis gases}

Our objective was to identify and discriminate between acetic acid and hydrochloric acid during the subsequent study of polymer mixtures. First we had to identify their presence absolutely - and thus their characteristic spectrum - during degradation of the individual polymers alone. The selected kinetic schemes showed that this was necessary for both EVA alone and PVC alone during the first step of degradation.

The gas cell of the infrared spectrophotometer was connected to the outlet of the thermograph oven by a temperature-regulated transfer line. The FT-IR analyzer via TimeBase provides the Gram-Schmidt profile of pyrolysis gas absorption versus time. It is interesting to be able to relate the FT-IR spectra analysis results to the weight variations recorded on the thermogram. We can express the relation between the time on the Gram-Schmidt profile corresponding to a recorded FT-IR spectrum for each time value $t$, and the sample temperature indicated on the thermogram. The Gram-Schmidt recording is electronically synchronized to

Table 5

VA percentages calculated from the plateau heights

\begin{tabular}{|c|c|c|c|c|c|}
\hline EVA type & $x\left(T_{\text {plateau }}\right)$ & VA\% (calculated) & VA\% (supplier) & Absolute error & Relative error \\
\hline EVA 90/10 & 0.95 & 7.17 & 10 & 2.83 & 0.283 \\
\hline EVA $80 / 20$ & 0.88 & 17.208 & 20 & 2.792 & 0.1396 \\
\hline EVA $70 / 30$ & 0.79 & 30.114 & 30 & -0.114 & -0.0038 \\
\hline EVA $60 / 40$ & 0.72 & 40.152 & 40 & -0.152 & -0.0038 \\
\hline EVA $50 / 50$ & 0.65 & 50.19 & 50 & -0.19 & -0.0038 \\
\hline EVA 40/60 & 0.59 & 58.794 & 60 & 1.206 & 0.0201 \\
\hline EVA $30 / 70$ & 0.53 & 67.398 & 70 & 2.606 & 0.03717 \\
\hline EVA $20 / 80$ & 0.48 & 74.568 & 80 & 5.432 & 0.0679 \\
\hline EVA $10 / 90$ & 0.45 & 78.87 & 90 & 11.13 & 0.1236 \\
\hline PVA & 0.41 & 84.606 & 100 & 15.394 & 0.153 \\
\hline
\end{tabular}

For EVA 30 to EVA 70, the relative error is thus less than 5\%, i.e. the extrapolation is perfectly acceptable. For higher vinyl acetate concentrations, a slight divergence can be observed.

Table 6

Weight losses, DTG values, and DTG peak temperatures for pure PVC

\begin{tabular}{|c|c|c|c|c|c|c|c|c|c|}
\hline \multirow[t]{2}{*}{ Heating rate $\left({ }^{\circ} \mathrm{C} \mathrm{min}^{-1}\right)$} & \multicolumn{3}{|c|}{ DTG peak temperature $\left({ }^{\circ} \mathrm{C}\right)$} & \multicolumn{3}{|c|}{ DTG value $(\% / \mathrm{min})$} & \multicolumn{3}{|c|}{ Weight loss $(\%)$} \\
\hline & First loss & Second loss & Third loss & First loss & Second loss & Third loss & First loss & Second loss & Third loss \\
\hline 5 & 270 & 325 & 458 & -9.5 & -1.2 & -2.2 & 56.3 & 10.9 & 25.6 \\
\hline 10 & 283 & 336 & 470 & -15.5 & -2.3 & -3.9 & 58.1 & 10 & 25.6 \\
\hline 20 & 300 & 350 & 480 & -22.3 & -6.3 & -6.5 & 58 & 10.6 & 24.4 \\
\hline 30 & 312 & - & 483 & -26.6 & - & -8.6 & 56.3 & 13.1 & 23.1 \\
\hline
\end{tabular}


Table 7

Weight losses, DTG values, and DTG peak temperatures for pure cellulose

\begin{tabular}{llll}
\hline $\begin{array}{l}\text { Heating rate } \\
\left({ }^{\circ} \mathrm{C} \mathrm{min}^{-1}\right)\end{array}$ & $\begin{array}{l}\text { DTG peak } \\
\text { temperature }\left({ }^{\circ} \mathrm{C}\right)\end{array}$ & $\begin{array}{l}\text { DTG value } \\
(\% / \mathrm{min})\end{array}$ & $\begin{array}{l}\text { Weight } \\
\text { loss }(\%)\end{array}$ \\
\hline 10 & 345 & -23.3 & 83 \\
30 & 364 & -37 & 83
\end{tabular}

start at the same time the thermal analyzer begins heating, designated $t_{0}$ for each test.

The temperature is then expressed versus time as follows:

$T\left({ }^{\circ} \mathrm{C}\right)=\frac{(\operatorname{tir}+\operatorname{trs}) \beta}{60}$

- tir: time in seconds corresponding to an FT-IR spectrum obtained from the Gram-Schmidt record.

- trs: transfer time in seconds of the evolved gas during pyrolysis from the TGA to the FT-IR gas cell (depending on the system setup and the vector gas flow rate; experimentally measured as $110 \mathrm{~s}$ ).

- $\beta$ : heating rate in ${ }^{\circ} \mathrm{C} \min ^{-1}$.

- $T\left({ }^{\circ} \mathrm{C}\right)$ : sample temperature recorded on the thermogram.

The Fourier transform for each time $t$ on the Gram-Schmidt profile yields the corresponding IR spectra, i.e. the characteristic curve of absorbance versus wave number for the products detected as they transited through the FT-IR cell at that exact time. The resulting spectra were analyzed with KnowItAll by comparison with databases containing the IR spectra of known compounds to identify the evolved gas.

In the following discussion, the terms "alkane or alkene compounds" (or simply "alkane" or "alkene") are used to designate the presence of saturated or unsaturated hydrocarbons, aromatic or nonaromatic, of variable length and structure, that have not been accurately identified.

Results are shown for thermal analyzer heating rates of $\beta=20$ and $30{ }^{\circ} \mathrm{C} \mathrm{min}{ }^{-1}$, as applicable, although the same results were obtained in this study with $\beta=5$ and $10^{\circ} \mathrm{C} \mathrm{min}^{-1}$.

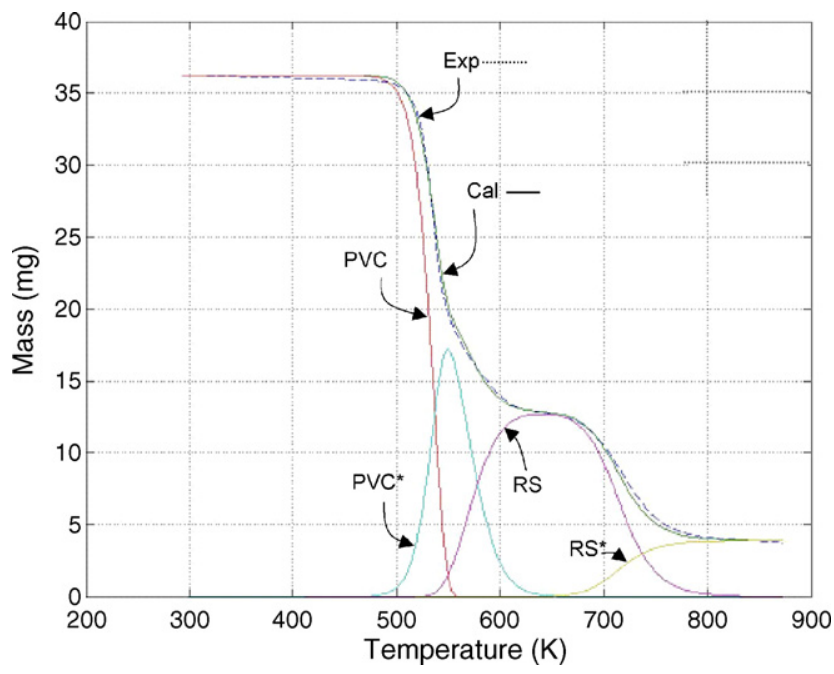

Fig. 4. Experimental and calculated curves for pure PVC $\left(K=10{ }^{\circ} \mathrm{C} \mathrm{min}{ }^{-1}\right)$.
Table 8

$f(X)$ functions applied to thermal degradation of solids

\begin{tabular}{ll}
\hline Model & $f(X)$ \\
\hline Reaction order & $(1-X)^{n}$ \\
$\quad n=0$ & \\
$n=1$ & \\
$n>1$ & \\
Geometric functions & $2(1-X)^{0.5}$ \\
$\quad$ Cylindrical symmetry & $3(1-X)^{2 / 3}$ \\
$\quad$ Spherical symmetry & \\
Diffusion functions & $1 / 2 X$ \\
$\quad$ One dimension & $(-\ln (1-X))^{-1}$ \\
$\quad$ Two dimensions & $1.5(1-X)^{2 / 3}\left(1-(1-X)^{1 / 3}\right)^{-1}$ \\
$\quad$ Three dimensions: & \\
$\quad$ Jander equation & $1.5\left((1-X)^{-1 / 3}-1\right)^{-1}$ \\
$\quad$ Three dimensions: & \\
$\quad$ Ginstling-Brounshtein & \\
Crystal growth & $n(1-X)(-\ln (1-X))^{(n-1) / n}$ \\
$\quad$ Avrami-Erofeev for $n=1.5,2,3$ & $(1-X) X^{n}$ \\
$\quad$ Prout-Tomkins for $n=0.5,1$ & \\
\hline
\end{tabular}

\subsubsection{FT-IR analysis of EVA pyrolysis gases}

Fig. 6 is the Gram-Schmidt diagram obtained by analysis with a heating rate of $20{ }^{\circ} \mathrm{C} \mathrm{min}{ }^{-1}$.

Several time values are identified in Fig. 6:

- $t_{1}=933.59 \mathrm{~s}, T_{1}=348{ }^{\circ} \mathrm{C}$ : beginning of EVA decomposition. At this point the FT-IR spectrum begins to display a few characteristic peaks of acetic acid.

- $t_{2}=1006.9 \mathrm{~s}, T_{2}=372{ }^{\circ} \mathrm{C}$ : intermediate time characterized by release of acetic acid. The online FT-IR spectrum corresponding to this point is shown in Fig. 7A.

- $t_{3}=1097.16 \mathrm{~s}, T_{3}=402{ }^{\circ} \mathrm{C}$ : time corresponding to maximum FT-IR absorption associated with maximum gas evolution. The FT-IR spectrum corresponding to this point is shown in Fig. 7B. For comparison, this spectrum (dotted line) is superimposed on the characteristic spectrum of acetic acid (solid line) from the KnowItAll database, confirming the

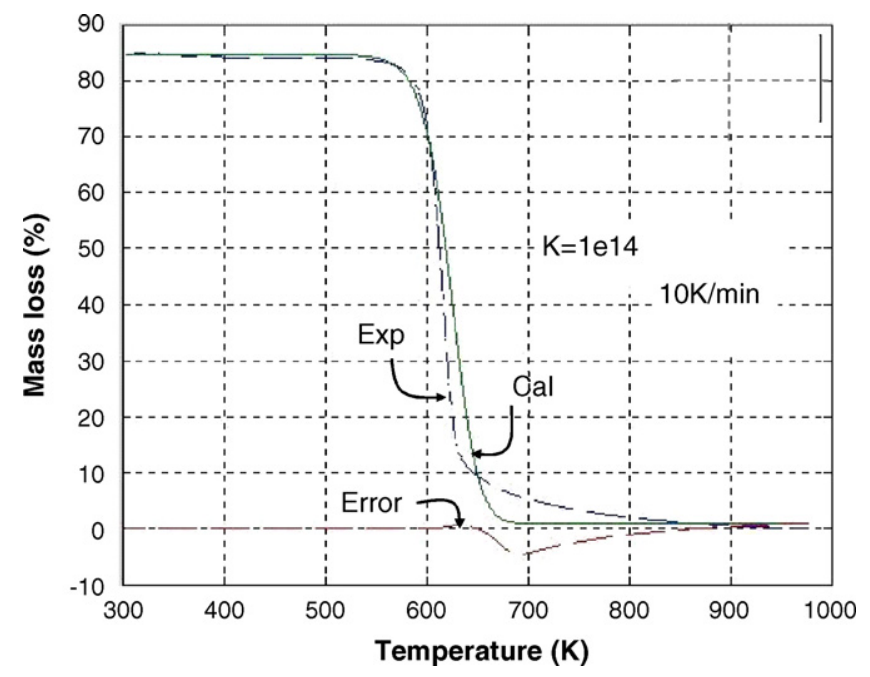

Fig. 5. Experimental and calculated curves for pure cellulose. 


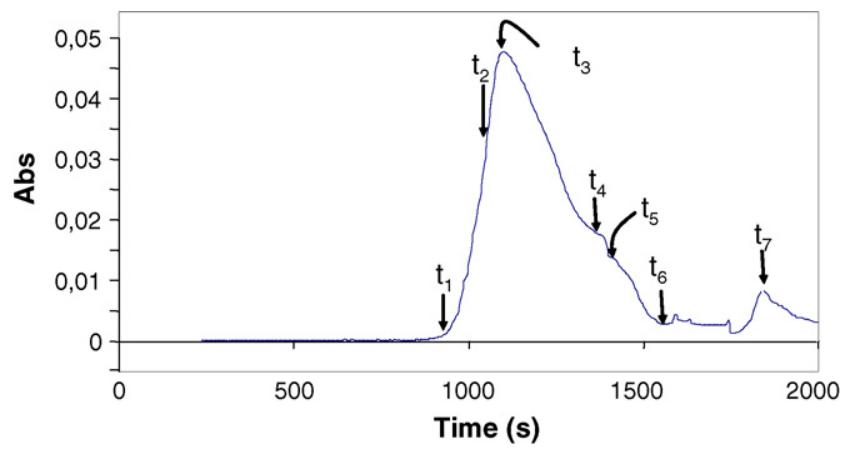

Fig. 6. Gram-Schmidt curve for EVA alone $\left(\beta=20^{\circ} \mathrm{C} \min ^{-1}\right)$.

formation of acetic acid during the first step of the kinetic mechanism proposed in the literature.

- $t_{4}=1385.52 \mathrm{~s}, T_{4}=498{ }^{\circ} \mathrm{C}$ : intermediate time characterized by a drop in the intensity of the characteristic peaks of acetic acid and the appearance of new peaks around $3000 \mathrm{~cm}^{-1}$. The corresponding FT-IR spectrum is shown in Fig. 7C and the new spectrum is illustrated in Fig. 8, revealing the presence of alkane and alkene compounds, notably the formation of A$\mathrm{CH}_{3}$ hydrocarbons. This corresponds to the beginning of the second step of EVA degradation.

It is well known that peaks under $3000 \mathrm{~cm}^{-1}$ are linked to sp3 carbon hybridization and peaks above $3000 \mathrm{~cm}^{-1}$ are linked to $\mathrm{sp} 2$ carbon hybridization. The variation of their intensity ratio indicates the proportions of alkane and alkene during the second degradation step.

- $t_{5}=1419.01 \mathrm{~s}, T_{5}=510{ }^{\circ} \mathrm{C}$ : intermediate time with an FT-IR spectrum similar to the one recorded at $t_{4}$.

- $t_{6}=1579.19 \mathrm{~s}, T_{6}=563{ }^{\circ} \mathrm{C}$ : corresponds to the GramSchmidt base. The relevant FT-IR spectrum (Fig. 7D) shows a major change in the shape of the spectrum around $3000 \mathrm{~cm}^{-1}$.

- $t_{7}=1837.34 \mathrm{~s}, T_{7}=649{ }^{\circ} \mathrm{C}$ : this point corresponds to the end of EVA degradation, with a spectrum similar to the one
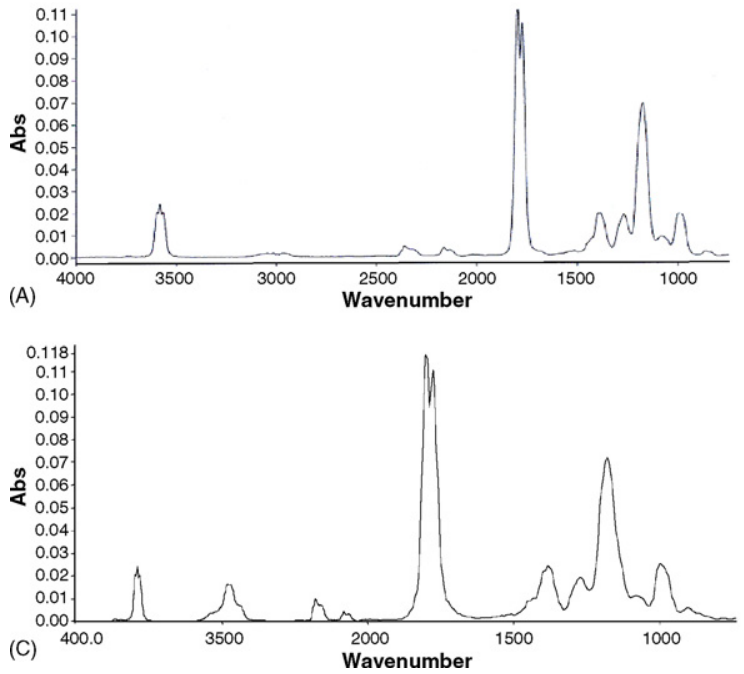

recorded at time $t_{6}$. At the end of the degradation process, there is a minor formation of characteristic peaks for alkene compounds that modify the spectrum around $3000 \mathrm{~cm}^{-1}$, in particular peaks at 3018 and $3049 \mathrm{~cm}^{-1}$ (the peaks between 1500 and $1000 \mathrm{~cm}^{-1}$ are also deformed). The corresponding FT-IR spectrum identifying the peaks is shown in Fig. 8.

3.4.1.1. Conclusions for EVA polymer. The tests demonstrated the effectiveness of online TGA/DTA and FT-IR measurements with very clear deconvolution and identification of the peaks obtained. FT-IR analysis of the evolved gas confirmed the existence of two steps in the EVA degradation process, and identified the formation of acetic acid during the first step and of alkane and alkene compounds during the second step. These results corroborate the selected kinetic mechanism for thermal degradation of EVA reported in the literature.

\subsubsection{FT-IR analysis of PVC pyrolysis gases}

Fig. 9 is the Gram-Schmidt diagram obtained by analysis with a heating rate of $30{ }^{\circ} \mathrm{C} \mathrm{min}{ }^{-1}$.

As with EVA, several characteristic time values were identified:

- $t_{1}=574 \mathrm{~s} ; T_{1}=342{ }^{\circ} \mathrm{C}$ : this point corresponds to the beginning of PVC degradation. The characteristic $\mathrm{HCl}$ peaks start to become perceptible on the FT-IR spectrum.

- $t_{2}=668.7 \mathrm{~s} ; T_{2}=389.4{ }^{\circ} \mathrm{C}$ : this point corresponds to the vertex of the first peak on the Gram-Schmidt curve. The corresponding FT-IR spectrum is shown in Fig. 10A. A series of peaks appears around $3000 \mathrm{~cm}^{-1}$, corresponding to the rotation spectrum of the $\mathrm{HCl}$ molecule identified in Fig. 10B. It may be noted that some peaks are superimposed on this group, i.e. the characteristic peaks of alkane or alkene compounds.

- $t_{3}=910.2 \mathrm{~s} ; T_{3}=510.1{ }^{\circ} \mathrm{C}$ : this point corresponds to the base of the large peak on the Gram-Schmidt diagram. The corresponding FT-IR spectrum is shown in Fig. 10C. At this
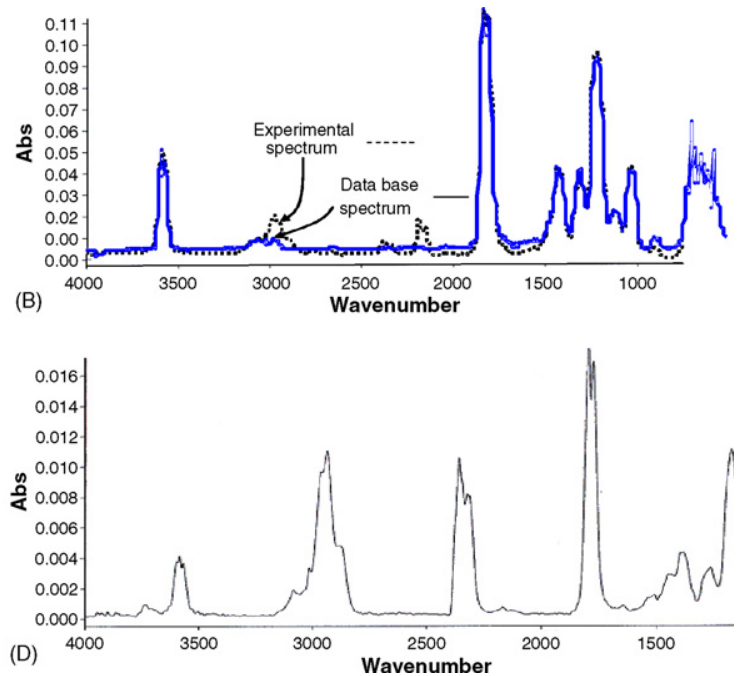

Fig. 7. IR absorption spectra recorded during EVA degradation for different time values on the Gram-Schmidt profile: $(\mathrm{A}) t_{2}=1007 \mathrm{~s} ;(\mathrm{B}) t_{3}=1097 \mathrm{~s} ;(\mathrm{C})$ $t_{4}=1386 \mathrm{~s}$; (D) $t_{6}=1579 \mathrm{~s}$. 


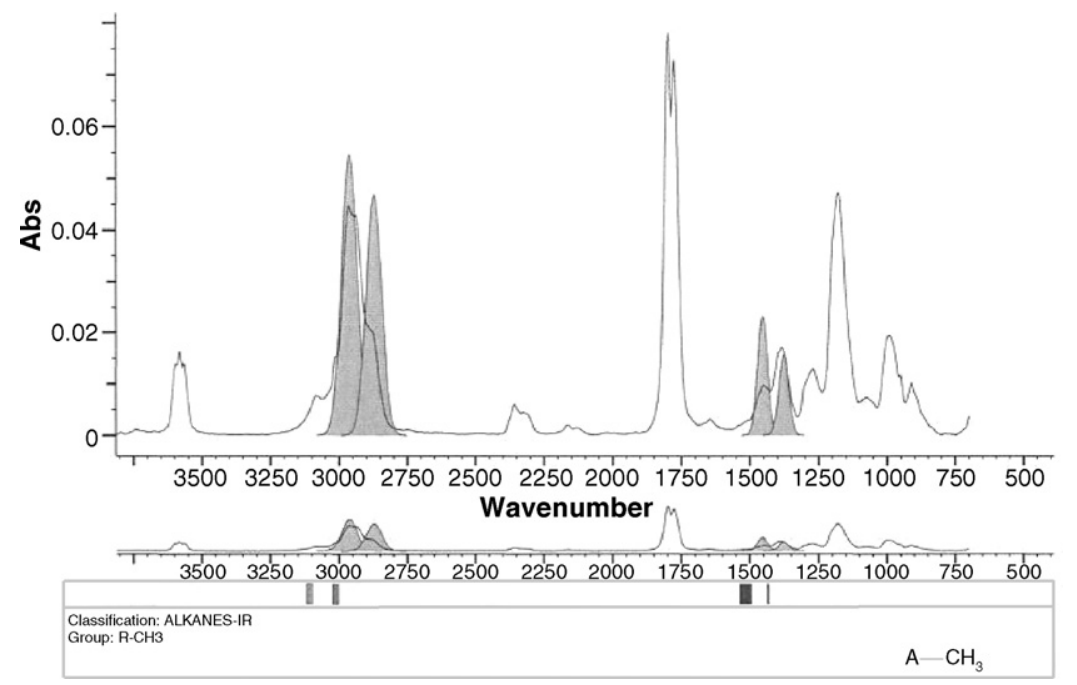

Fig. 8. Partial identification of peaks appearing on FT-IR spectrum for point $t_{7}$. Alkane and alkene compounds are identified among the peaks near $3000 \mathrm{~cm}^{-1}$ and in the region between 1500 and $1000 \mathrm{~cm}^{-1}$.

level, alkane and alkene compounds generate peaks of increasing amplitude that gradually mask the $\mathrm{HCl}$ rotation spectrum. This superimposition accounts for the difference observed between the two spectra in Fig. 10B. The massive appearance of these peaks corresponds to the second step of the $\mathrm{HCl}$ degradation mechanism.

- $t_{4}=957.6 \mathrm{~s} ; T_{4}=533.8{ }^{\circ} \mathrm{C}$ : this point corresponds to the vertex of the second peak on the Gram-Schmidt curve. The corresponding FT-IR spectrum is shown in Fig. 10D. The $\mathrm{HCl}$ rotation spectrum disappears as the other peaks increase in size.

The FT-IR spectra corresponding to longer time values on the Gram-Schmidt diagram are similar to those recorded at $t_{4}$ with gradually diminishing peak intensities.

3.4.2.1. Conclusions for PVC. As with EVA, the results show that coupling TGA/DTA and FT-IR provides substantial amounts of data as well as spectra of high quality. In the case of PVC, the series of spectra corroborate the existence of

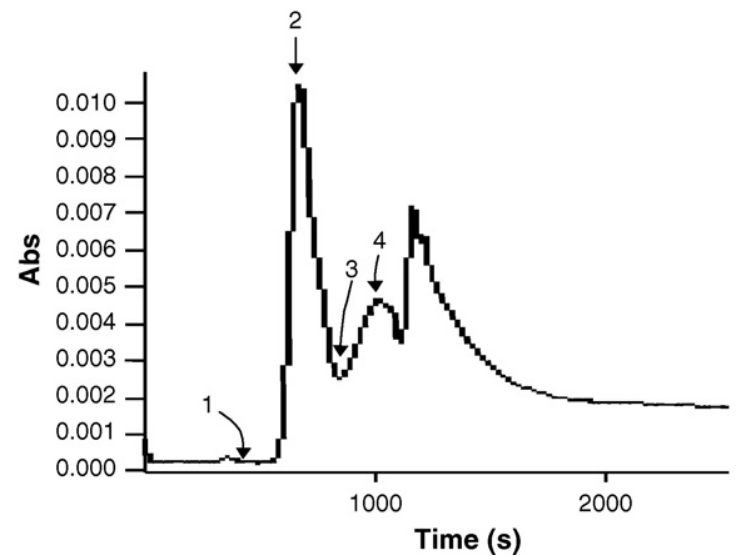

Fig. 9. Gram-Schmidt curve obtained during pyrolysis of PVC pure $\left(\beta=30^{\circ} \mathrm{C} \mathrm{min}^{-1}\right)$. two degradation steps: an initial dehydrochlorination step during which hydrochloric acid $(\mathrm{HCl})$ forms, followed by the formation of alkane and alkene compounds corresponding to degradation of the carbon chain.

\subsubsection{Pure cellulose}

The most commonly accepted mechanism for the pyrolytic degradation of cellulose postulates a single step during which several compounds are formed; the most important of these are water vapor, carbon dioxide $\mathrm{CO}_{2}$, carbon monoxide $\mathrm{CO}$, and hydrocarbon derivatives such as alkanes, alkenes, ketones and aldehydes. These compounds can be identified from the characteristic peaks in Table 9.

The ketones and aldehydes have a strong absorption band for the elongation of the $\mathrm{C}=\mathrm{O}$ group between 1870 and $1540 \mathrm{~cm}^{-1}$. Its relatively constant position, high intensity and independence with respect to interfering bands make it one of the easiest bands to recognize in IR spectra. Within its frequency range, the position of the $\mathrm{C}=\mathrm{O}$ elongation band is determined by the following factors: (1) the physical state, (2) electronic and mass effects of neighboring substituents, (3) conjugation, (4) interand intramolecular hydrogen bridges, and (5) the ring tension. Allowing for these factors results in a substantial mass of data concerning the environment of the $\mathrm{C}=\mathrm{O}$ group. The aldehydes absorb at slightly higher frequencies than the methyl ketones. The aliphatic aldehydes absorb between 1740 and $1720 \mathrm{~cm}^{-1}$. The absorption of the aldehyde carbonyl group responds to structural variations in the same way as the ketones.

Fig. 11 shows the Gram-Schmidt profile obtained with pure cellulose. The shape of the Gram-Schmidt profile is relatively simple compared with the diagrams for EVA or PVC. Three distinct time values were identified:

- $t_{1}=566.4 \mathrm{~s}, T_{1}=338.2{ }^{\circ} \mathrm{C}$ : this point corresponds to the beginning of cellulose degradation. The FT-IR spectrum corresponding to this point is shown in Fig. 12A. Characteristic spectral peaks of $\mathrm{CO}, \mathrm{CO}_{2}$ and water vapor can be 

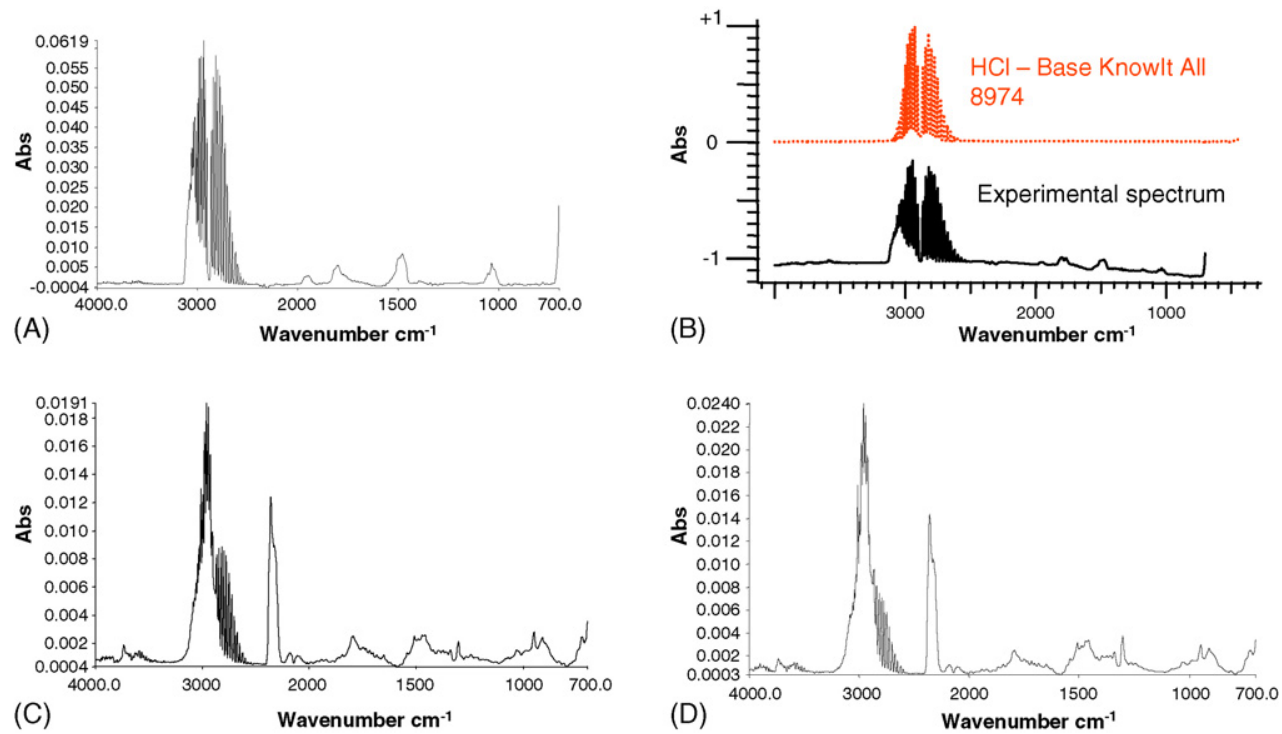

Fig. 10. IR absorption spectra recorded during PVC degradation for different time values on the Gram-Schmidt profile: (A) $t_{2}=669 \mathrm{~s}$; (B and C) $t_{3}=910 \mathrm{~s}$; (D) $t_{4}=958 \mathrm{~s}$.

distinguished; as they are native peaks, they are of low amplitude compared with the background.

- $t_{2}=767.1 \mathrm{~s} ; T_{2}=438.6{ }^{\circ} \mathrm{C}$ : this point corresponds to the vertex of the peak on the Gram-Schmidt curve. The corresponding FT-IR spectrum (Fig. 12B) shows a very significant increase in the intensity of the $\mathrm{CO}$ and $\mathrm{CO}_{2}$ peaks. - $t_{3}=934.9 \mathrm{~s} ; T_{3}=522.45{ }^{\circ} \mathrm{C}$ : this point is midway along the trailing edge of the Gram-Schmidt peak. The FT-IR spectrum corresponding to this point is shown in Fig. $12 \mathrm{C}$. The $\mathrm{CO}_{2}$ peak is still largely present, but characteristic peaks of alkane, alkene and ketone compounds appear around $3000 \mathrm{~cm}^{-1}$ and between 1500 and $2000 \mathrm{~cm}^{-1}$. Fig. 12D identifies the ketone compounds.

These observations show that the degradation of cellulose begins with the formation of the characteristic peaks of $\mathrm{CO}_{2}$, $\mathrm{CO}$ and water vapor, which become increasingly clear over time. The TGA thermograms revealed a first weight loss at about $336{ }^{\circ} \mathrm{C}$, followed by a second much greater weight loss above $350{ }^{\circ} \mathrm{C}$, i.e. after $590 \mathrm{~s}$ at a heating rate of $30{ }^{\circ} \mathrm{C} \mathrm{min}{ }^{-1}$. Examining the FT-IR spectra over time revealed changes in the characteristic compounds of cellulose degradation: first $\mathrm{CO}$, $\mathrm{CO}_{2}$ and water vapor, followed by various alkanes, alkenes, aldehydes and ketones.

Table 9

Characteristic wave numbers of various compounds

\begin{tabular}{ll}
\hline Compound & Wave number $\left(\mathrm{cm}^{-1}\right)$ \\
\hline $\mathrm{CO}_{2}$ & $2400-2200$ \\
$\mathrm{CO}$ & $2200-2000$ \\
$\mathrm{H}_{2} \mathrm{O}$ & $3750-3500$ \\
$\mathrm{C}_{n} \mathrm{H}_{2 n+2}$ & $2800-3000$ \\
$\mathrm{C}_{n} \mathrm{H}_{2 n}$ & $3050-3150$ \\
Ketones & $1690-1750$ \\
Aldehydes & $1740-1800$ \\
\hline
\end{tabular}

3.4.3.1. Conclusion for cellulose. Although the degradation of cellulose proved more difficult to investigate than that of the other polymers described above, we were able to better understand its behavior. We confirmed published reports of the existence, during cellulose degradation, of a first weight loss resulting in the formation mainly of $\mathrm{CO}, \mathrm{CO}_{2}$ and water vapor, followed by a second much more significant weight loss during which various aldehydes and aromatic compounds are formed, as well as ketones, alkanes and alkenes. These phenomena were observed by coupling DTA, TGA and FT-IR; they corroborate the hypotheses postulated in the framework of the degradation mechanism proposed by Broido-Shafizadeh, which predicts not only the formation of a carbon compound together with an evolved gas $\left(\mathrm{CO}_{2}, \mathrm{CO}\right)$ but also the formation of volatile compounds.

Given the importance of the $\mathrm{CO}_{2}$ emission peak, it may be advantageous to monitor cellulose degradation simple by monitoring this compound. Fig. 13 plots the characteristic $\mathrm{CO}_{2}$ absorption versus time: the shape of the peak obtained closely follows the Gram-Schmidt profile in Fig. 13.

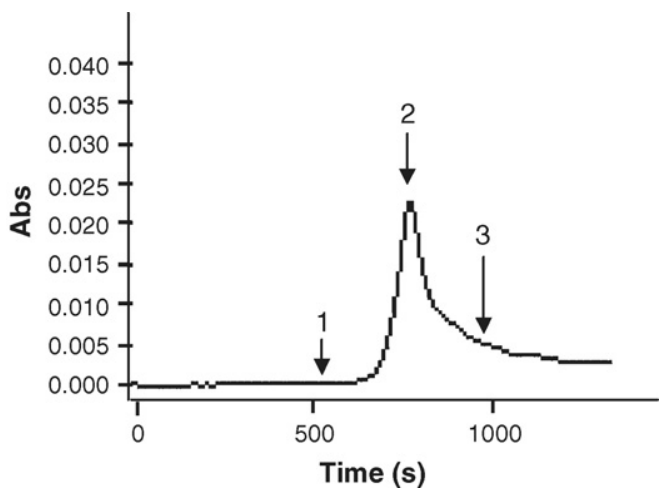

Fig. 11. Gram-Schmidt curve of evolved gas from the degradation of pure cellulose at $30{ }^{\circ} \mathrm{C} \mathrm{min}{ }^{-1}$. 

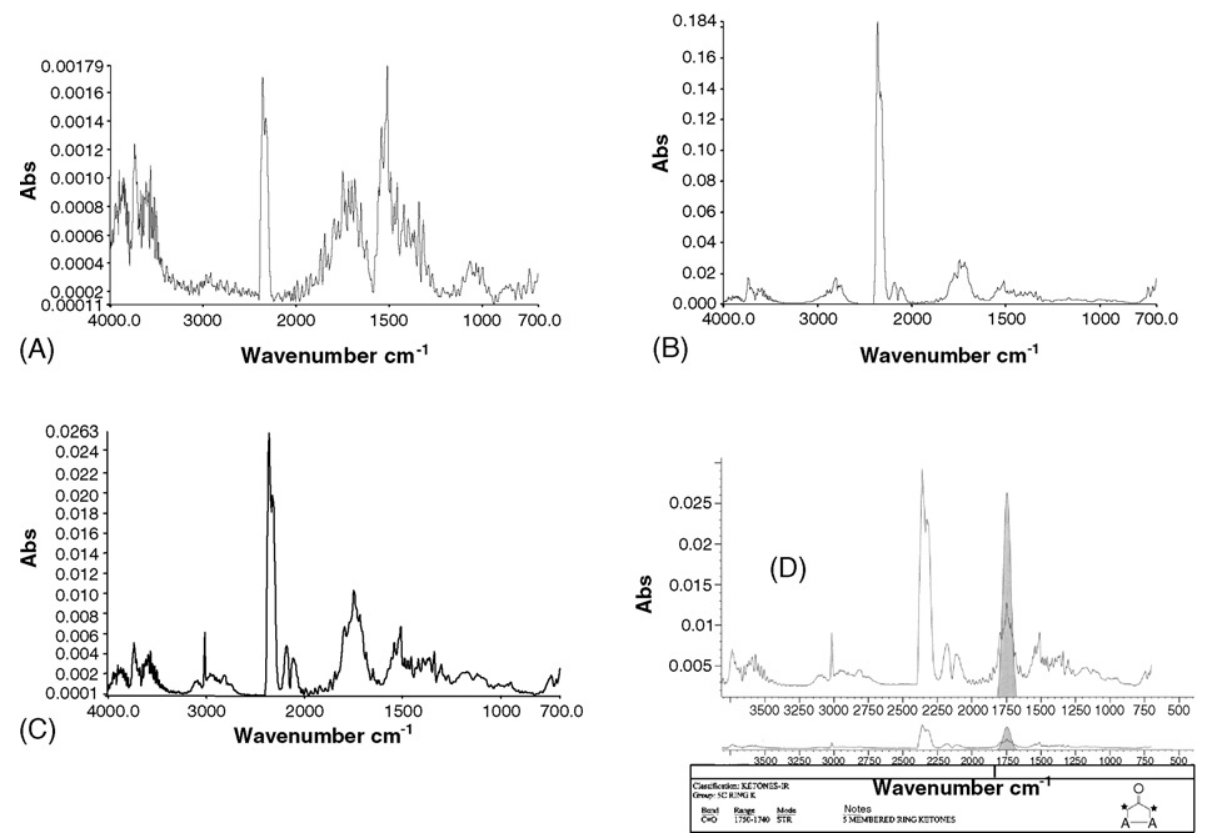

Fig. 12. IR absorption spectra recorded during cellulose degradation for different time values on the Gram-Schmidt profile: (A) $t_{1}=566 \mathrm{~s}$; (B) $t_{2}=676 \mathrm{~s}$; (C and D) $t_{3}=935 \mathrm{~s}$.

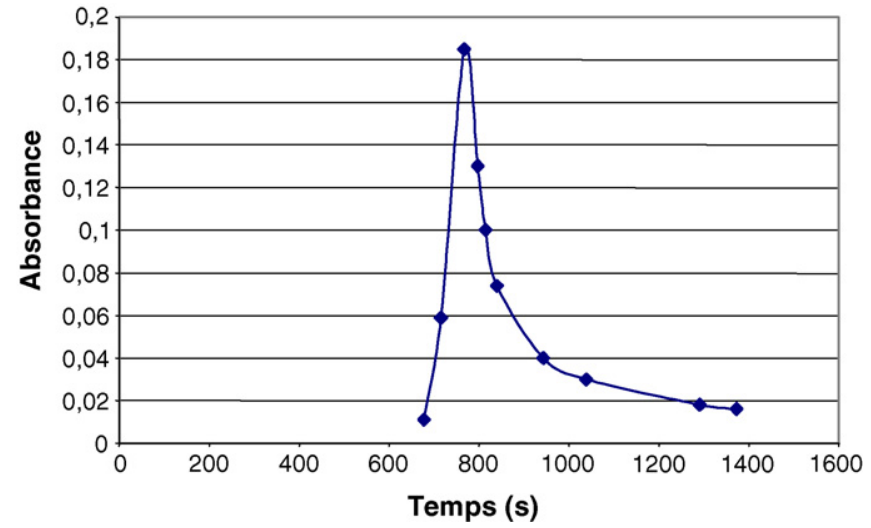

Fig. 13. $\mathrm{CO}_{2}$ absorption vs. time during cellulose degradation at $30{ }^{\circ} \mathrm{C} \mathrm{min}^{-1}$.

\section{Conclusion}

The results discussed in this paper constitute the first part of an investigation of the pyrolytic degradation of mixed polymers. In this part we examined the degradation of individual polymers to develop a method coupling thermogravimetric analysis and infrared analysis to monitor the main stages in the weight loss of the test compounds and identify the evolved gas. The experimental results confirmed the effectiveness and advantages of this type of coupling.

Simulation with selected models already described in the literature gave very satisfactory results, especially for EVA and PVC. In the case of EVA, acetic acid was formally identified during the first degradation step both by IR analysis and by calculating the weight loss from the TGA curves (the molar weight of the evolved gas corresponds to that of acetic acid). We also assessed the reliability of the model by recomputing the VA weight percentage in three EVA samples from the TGA/ DTA diagrams using a simple relation. This was also the case for the formation of hydrochloric acid during the first step of PVC degradation. Cellulose behavior was more complex, although $\mathrm{CO}_{2}$ and water vapor were clearly present from the outset of the degradation process. Complex mixtures of compounds predicted by the Broido-Shafizadeh degradation model are more difficult to analyze, but FT-IR analysis suggests the presence of alkane, alkene and ketone compounds.

\section{References}

[1] D. Munteanu, S. Turcu, Materiale Plastice 14 (1977) 3.

[2] N.S. Allen, M. Edge, M. Rodriguez, C.M. Liauw, E. Fontan, Polym. Degrad. Stab. 68 (2000).

[3] N.S. Allen, M. Edge, M. Rodriguez, C.M. Liauw, E. Fontan, Polym. Degrad. Stab. 71 (2000).

[4] D. Munteanu, S. Turcu, J. Therm. Anal. (1981)

[5] S.K. Dutta, A.K. Bhowmick, P.G. Mukunda, T.K. Chaki, Polym. Degrad. Stab. (1995).

[6] M. Shimoyama, H. Maeda, K. Matsukawa, H. Inoue, T. Ninomiya, Y. Ozaki, Vib. Spectrosc. (1997).

[7] K.R. Williams, J. Chem. Educ. (1994).

[8] Z. Wenwei, Z. Xiaoguang, Y. Li, Z. Yuefang, S. Jiazhen, Polymer 35 (1994) 15.

[9] M.B. Maurin, L.W. Dittert, A.A. Hussain, Thermochim. Acta (1991).

[10] M.B. Maurin, J. Wai, C. Pang, M.A. Hussain, Thermochim. Acta (1992) 5.

[11] B.J. McGrattan, Soc. Appl. Spectrosc. 48 (1994) 12.

[12] L.M. Cunha, F.A.R. Oliveira, J. Food Eng. (2000).

[13] McNeill, Comprehensive Polymer Science, vol. 6, Pergamon Press, Oxford, 1989.

[14] S.K. Dutta, A.K. Bhowmick, P.G. Mukunda, T.K. Chaki, Polym. Degrad. Stab. 50 (1995) 75-82.

[15] E.J. Moskala, D.W. Lee, Polym. Degrad. Stab. 25 (1989) 1

[16] D. Munteanu, S. Turcu, J. Therm. Anal. 20 (1981) 281.

[17] A. Marcilla, M. Beltran, Polym. Degrad. Stab. 50 (1995) 117-124. 
[18] U.K.O. Schröder, K.H. Ebert, A.W. Hamielec, Makromol. Chem. 185 (1984) 991.

[19] A. Marcilla, M. Beltran, Polym. Degrad. Stab. 48 (1995) 219-229.

[20] R. Knuemann, H. Bockhorn, Combust. Sci. Technol. (1994) 101-285.

[21] C. Hssiung, C.Y. Chang, J.L. Hor, Waste Manage. 13 (1993) 221-235.

[22] H. Bockhorn, A. Hornung, U. Hornung, S. Teepe, J. Weichmann, Combust. Sci. Tech. 116/117 (1996) 129-151.

[23] G. Matuschek, N. Milanov, A. Kettrup, Thermochim. Acta 361 (2000) 7784.

[24] R. Miranda, J. Yang, C. Roy, C. Vasile, Polym. Degrad. Stab. 64 (1999) 127-144.

[25] M. Mehl, A. Marongui, T. Favarelli, G. Bozzano, M. Dente, E. Ranzi, J. Anal. Appl. Pyrolysis 72 (2004) 253-272.

[26] Y. Matsuzawa, M. Ayabe, J. Nishino, Polym. Degrad. Stab. 7 (2001) 435444.
[27] J.A. Conesa, J.A. Caballero, A. Marcilla, R. Font, Thermochim. Acta 254 (1995) 175-192.

[28] A.N. Garcia, A. Marcilla, R. Font, Thermochim. Acta 254 (1995) 277304.

[29] J.A. Caballero, R. Font, A. Marcilla, Thermochim. Acta 276 (1996) 5777.

[30] C. Di Blasi, JAAP 47 (1998) 43-64.

[31] Khezami, Capart, 9e Congrès SFGP St Nazaire, France, September 9-11, 2003.

[32] A. Fontana, La thermolyse au service du traitement des déchets: Actualité et perspectives, Université Libre de Bruxelles, Faculté des Sciences Appliquées, Faculté des Sciences Sociales, Politiques et Economiques, Ecole de Commerce Solvay, EFE-Paris, October 1998.

[33] A. Fontana, Ph. Laurent, C. Kestemont, C. Braekman-Danheux, Erdöl Erdgas Kohle 116 (2) (2000) 89-92. 